J. Dairy Sci. 97:2959-2964

http://dx.doi.org/10.3168/jds.2013-7523

(C) American Dairy Science Association ${ }^{\circledR}, 2014$.

\title{
Short communication: Prevalence of methicillin resistance in coagulase-negative staphylococci and Staphylococcus aureus isolated from bulk milk on organic and conventional dairy farms in the United States
}

\author{
K. M. Cicconi-Hogan, ${ }^{\star 1,2}$ N. Belomestnykh, ${ }^{*}$ M. Gamroth,† P. L. Ruegg, $\neq$ L. Tikofsky, ${ }^{* 3}$ and Y. H. Schukken ${ }^{\star}$ \\ *Department of Population Medicine and Diagnostic Sciences, Cornell Veterinary Medicine, Cornell University, Ithaca, NY 14853 \\ †Department of Animal Sciences, Oregon State University, Corvallis 97331 \\ ‡Department of Dairy Science, University of Wisconsin-Madison, Madison 53706
}

\section{ABSTRACT}

The objective of this study was to evaluate the presence of methicillin-resistant Staphylococcus aureus and coagulase-negative Staphylococcus spp. in bulk tank milk samples from 288 organic and conventional dairy farms located in New York, Wisconsin, and Oregon from March 2009 to May 2011. Due to recent publications reporting the presence mecC (a mecA homolog not detected by traditional $m e c A$-based PCR methods), a combination of genotypic and phenotypic approaches was used to enhance the recovery of methicillin-resistant organisms from bulk tank milk. In total, 13 isolates were identified as methicillin resistant: Staph. aureus $(\mathrm{n}=1)$, Staphylococcus sciuri $(\mathrm{n}=5)$, Staphylococcus chromogenes $(\mathrm{n}=2)$, Staphylococcus saprophyticus (n $=3)$, Staphylococcus agnetis $(\mathrm{n}=1)$, and Macrococcus caseolyticus $(\mathrm{n}=1)$. The single methicillin-resistant Staph. aureus isolate was identified from an organic farm in New York, for an observed $0.3 \%$ prevalence at the farm level. The methicillin-resistant coagulase-negative staphylococci prevalence was $2 \%$ in the organic population and $5 \%$ in the conventional population. We did not identify mecC in any of the isolates from our population. Of interest was the relatively high number of methicillin-resistant Staph. sciuri recovered, as the number of isolates from our study was considerably higher than those recovered from other recent studies that also assessed milk samples. Our research suggests that the presence of a potential methicillin-resistant Staphylococcus reservoir in milk, and likely the dairy

Received September 24, 2013.

Accepted January 7, 2014.

${ }^{1}$ Corresponding author: kmc277@cornell.edu

${ }^{2}$ Current affiliation: United States Department of Agriculture, Agricultural Research Service, Russell Research Center, Poultry Processing and Swine Physiology Research Unit, Athens, GA 30605.

${ }^{3}$ Current affiliation: Boehringer Ingelheim Vetmedica Inc., St. Joseph, MO 64506. farm population in the United States, is independent of the organic or conventional production system.

Key words: dairy, organic, methicillin resistance, Staphylococcus

\section{Short Communication}

The organic dairy industry has seen rapid growth from 2000 to 2008, and has since been a consistently large contributor to the dairy industry (USDA-ERS, 2013). Organic milk quality, management, and animal health have been assessed in comparison with conventionally managed dairy farms (Zwald et al., 2004; Ruegg, 2009; Cicconi-Hogan et al., 2013a,b; Richert et al., 2013; Stiglbauer et al., 2013). Antimicrobial resistance in agriculture has become a major concern among consumers and scientists alike, as it presents potential health risks to animals and humans. The lack of use of antimicrobials on organic farms and how prevalent antimicrobial-resistant organisms are in relation to conventional farms is of interest, as is the possibility of various antimicrobial-resistant microorganisms in milk.

Staphylococcus aureus is a major mastitis-causing pathogen on dairy farms and has been found more frequently on organic dairy farms than conventional farms in recent studies (Ruegg, 2009; Cicconi-Hogan et al., 2013b). Methicillin-resistant Staph. aureus (MRSA) is of major concern in the human population, as it is difficult to treat. The mecA gene confers methicillin resistance by encoding a penicillin-binding protein, known as PBP-2 $\alpha$. It is located on a mobile element called staphylococcal cassette chromosome, known as SCCmec, which allows other species of Staphylococcus to pick up the methicillin resistance. Although detection of MRSA in bulk tank milk is often performed with molecular methods searching for a single conserved cassette (Virgin et al., 2009; Haran et al., 2012), recent research has found a variant that is undetectable through these methods. A divergent homolog, $m e c A_{\mathrm{LGA} 251}$ has been described in García-Álvarez et al. (2011) and in 
Paterson et al. (2012) that only presents $70 \%$ similarity at the DNA level to the traditional mecA gene, and is officially identified as mecC (Ito et al., 2012).

Methicillin-resistant Staph. aureus has been isolated from bulk tank and quarter milk samples in Europe (Spohr et al., 2011; Kreausukon et al., 2012), but the MRSA detection rate in bulk tank milk in the United States is quite low (Virgin et al., 2009; Haran et al., 2012). Although research has been done on MRSA and methicillin-resistant CNS (MRCNS) at the cow level in the United States (Tikofsky et al., 2003) and in limited geographical locations (Sato et al., 2004), no research has specifically targeted MRSA or MRCNS in organically produced milk at the herd level in a representative sample of the organic dairy population from across the United States. Due to the mobile nature of SCCmec, assessing the prevalence of MRCNS in bulk tank milk is of interest. The objective of this study, which was part of a larger project designed to assess differences between organic and conventional dairy farms, was to assess the presence of MRSA and MRCNS in bulk tank milk samples from New York, Wisconsin, and Oregon.

\section{Data and Sample Collection}

Herd inclusion, eligibility, and recruitment criteria are described in Cicconi-Hogan et al. (2013a), Richert et al. (2013), and Stiglbauer et al. (2013). Following recruitment and a matching period, 192 organic and 100 conventional farms in New York, Oregon, and Wisconsin were visited between March 2009 and May 2011. The conventional farms were included in the study based on proximity to the organic farms and were matched based on herd size category (0-99 adult cows, 100-199 adult cows, or $\geq 200$ adult cows). Farms were compensated with bulk tank milk testing and testing of clinical mastitis samples. At the time of the visit, a questionnaire was administered to the person primarily responsible for farm management and animal health. More detailed information on the questionnaire can be found in other published material from the study (Cicconi-Hogan et al., 2013a,b; Richert et al., 2013; Stiglbauer et al., 2013) and at the project website (http://milkquality.wisc. edu/organic-dairies/project-c-o-w/).

Six bulk tank milk samples were collected from each farm at the time of the visit. After the bulk tank had been agitated for a minimum of $5 \mathrm{~min}$, all samples were taken directly from the bulk tank with a sterile sampler, put on ice, and transported to Quality Milk Production Services (Ithaca, NY) for testing. Of the 292 farms visited, 2 farmers requested that their bulk tanks not be sampled or analyzed, and 2 samples were unable to be analyzed, leaving a total of 288 samples. All samples were kept frozen at $-20^{\circ} \mathrm{C}$ until testing.

\section{Genotypic and Phenotypic Testing for MRSA and MRCNS}

Two parallel assays were performed to assess the presence of methicillin-resistant organisms in the bulk tank milk. A genotypic approach (Virgin et al., 2009) was initially used to determine if the nuc gene, which encodes the thermostable nuclease of Staph. aureus (Brakstad et al., 1992), and a 174-bp portion of the $m e c A$ gene (Martineau et al., 2000), were present in the isolates cultured from the bulk tank milk. Approximately $20 \mu \mathrm{L}$ of milk was swabbed onto Trypticase soy agar with $5 \%$ sheep blood and $0.1 \%$ esculin (bioMérieux Inc., Durham, NC), and incubated at $37^{\circ} \mathrm{C}$. Plates were assessed for growth at 24 and $48 \mathrm{~h}$. Colonies were initially identified as Staphylococcus spp. by appearance, hemolysis, catalase and coagulase production, and UV light assessment, and were then isolated on blood agar plates. Up to 10 colonies per sample were isolated for further testing. DNA templates from all isolates in the study were obtained using a Qiagen DNA Mini Kit (Qiagen Inc., Valencia, CA), according to the procedure for gram-positive bacterial organisms. All PCR reactions in this study were done on an iCycler (Bio-Rad Laboratories Inc., Hercules, CA). The PCR protocol was run as described in Virgin et al. (2009). A negative lysate preparation and a negative for the PCR reaction served as the negative controls for the experiment. The positive control used was strain QMP S1-027 (Virgin et al., 2009), an MRSA isolate from heifer milk that was $m e c A$ and nuc positive, confirmed by PCR (a gift of J. Barlow, University of Vermont, Burlington).

Concomitantly, a phenotypic approach was used to enhance the recovery of MRSA and MRCNS from the milk and to identify methicillin-resistant genotypes other than those that could be identified with the previously described PCR protocol. Milk samples were defrosted overnight at $4^{\circ} \mathrm{C}$. To encourage the growth of Staphylococcus spp., a 2-step selective enrichment method was used (Haran et al., 2012). In brief, $10 \mathrm{~mL}$ of milk was added to $40 \mathrm{~mL}$ of Mueller-Hinton broth with $6.5 \% \mathrm{NaCl}$, and the samples were incubated for $24 \mathrm{~h}$ at $37^{\circ} \mathrm{C}$. One milliliter of the initial broth was added to $9 \mathrm{~mL}$ of phenol red mannitol broth (with $75 \mathrm{mg}$ of aztreonam/ $\mathrm{mL}$ and $5 \mathrm{mg}$ of cefoxitin/mL), and was incubated at $37^{\circ} \mathrm{C}$ for $24 \mathrm{~h}$. Then, $100 \mu \mathrm{L}$ of the resulting culture was spread onto MRSASelect plates (Bio-Rad Laboratories Inc., Redmond, WA) and incubated for $24 \mathrm{~h}$ at $37^{\circ} \mathrm{C}$. The plates were assessed for pink colonies, indicating MRSA, or for off-white colonies, indicating MRCNS. All resulting colonies were replated on MRSASelect plates to confirm growth and on blood agar plates to reevaluate Staphylococcuslike colonies for appearance. Isolates were tested for 
catalase and coagulase production and DNA templates from all colonies were obtained. The negative controls were Staph. aureus ATCC 25923 (where ATCC is the American Type Culture Collection strain), a negative $\mathrm{PCR}$ reaction, and negative lysates prepared using no DNA. Positive controls used were MRSA strain ATCC 33591 and MRSA strain ATCC BAA-2312 (to assess for $\operatorname{mec} C$ ).

Although MRSASelect plates have been established as an effective selective media for isolating methicillinresistant Staphylococcus spp. (Carson et al., 2009; Wolk et al., 2009), we recognize that some potential pitfalls exist. Chromogenic agars are generally subjective, as the individual reading the plates must assess the color of the colonies. Therefore, it is possible that the previously identified isolates containing mecC may not produce the same type of coloration as an MRSA isolate, resulting in a dismissal for further identification. Additionally, we used a traditional microbiological method to identify staphylococcal isolates by their morphological characteristics. We recognize the potential for missing MRSA isolates using this method, as several hundred staphylococcal colonies may be present on a single plate. We also recognize the potential for missing non-hemolytic CNS on blood agar media, but believe that the alternate testing we used minimized that.

All isolates from both approaches were identified using $16 \mathrm{~S}$ rRNA and rpoB speciation. The primers and $\mathrm{PCR}$ protocol used for the $16 \mathrm{~S}$ rRNA amplification is described in Greisen et al. (1994). The PCR protocol and primers used for rpoB (primer names: $2643 \mathrm{~F}$ and 3241R) are described in Drancourt and Raoult (2002). Following the PCR, the products were cleaned up using ExoSAP-IT PCR Product Cleanup (USB Products; Affymetrix Inc., Cleveland, $\mathrm{OH}$ ) according to the manufacturer's directions. The samples were sent to Cornell University Core Laboratories Center (Ithaca, NY), where they were processed using Sanger/3730XL DNA sequencing. Sequences were analyzed using Lasergene SeqMan software (DNASTAR Inc., Madison, WI) and then compared for sequence similarity to other sequences using the BLAST database [National Center for Biotechnology Information (NCBI), Bethesda, MD; http://blast.ncbi.nlm.nih.gov/Blast.cgi].

All DNA confirmed as Staph. aureus or other Staphylococcus spp. were then tested to reconfirm the presence of the mecA gene. The presence of $f e m B$ was also examined, as it encodes a protein that influences the level of methicillin resistance of Staphylococcus. The primers and PCR protocol that were used for femB are described in Pérez-Roth et al. (2001). Testing for mecC was done using primers from Paterson et al. (2012). The PCR protocol used was as follows: an initial denaturation step at $94^{\circ} \mathrm{C}$ for $5 \mathrm{~min}$; 30 cycles of denaturing at $94^{\circ} \mathrm{C}$ for $1 \mathrm{~min}$, annealing at $55^{\circ} \mathrm{C}$ for $1 \mathrm{~min}$, and extension at $72^{\circ} \mathrm{C}$ for $2 \mathrm{~min}$; and a final extension at $72^{\circ} \mathrm{C}$ for $5 \mathrm{~min}$. No positive results from the $\operatorname{mec} C$ testing were found.

To rule out potential contamination of any potentially positive field samples by our MRSA-positive controls, we used a random amplification of polymorphic DNA (RAPD) protocol to determine strain differences as previously described (Gurjar et al., 2012). We used multilocus sequence typing (MLST) to further characterize the MRSA-positive suspect isolates in comparison with the mecA-positive control. The protocol used is described in Enright et al. (2000). The resulting sequences were proofread and trimmed according to the proper length for each housekeeping gene and then entered into the MLST database (http://saureus. beta.mlst.net). A strain type (ST) was assigned to the organisms based on the results.

\section{Prevalence of MRCNS and MRSA}

The farm identification, isolate identity, farm location, organic status, and testing results of all the isolates described below are shown in Table 1. Isolates shown are those that were positive through genotypic or phenotypic testing. Of the 11 MRCNS isolates that were detected, 3 were isolated from a single farm (Table 1 , farm 3, isolates $\mathrm{C}-\mathrm{E}$ ), 3 were isolated from another farm (Table 1, farm 4, isolates $\mathrm{F}-\mathrm{H}$ ), and the remaining isolates were from unique farms. In total, isolates were detected from 9 unique farms for a farm-level prevalence of $3 \%$ (exact CI: 1.4-5.6\%). The 2 Staphylococcus chromogenes isolates found on farm 3 were RAPD typed and were determined to be different isolates. One methicillin-resistant Macrococcus caseolyticus isolate was recovered. Isolates were identified as follows, with a minimum $98 \%$ out of $100 \%$ sequence identify to rpoB reference genes: Staphylococcus sciuri $(\mathrm{n}=5)$, Staph. chromogenes $(\mathrm{n}=2)$, Staph. saprophyticus $(\mathrm{n}=3)$, and Staph. agnetis $(\mathrm{n}=1)$. All isolates were catalase positive and coagulase negative, negative for $\mathrm{fem} B$, and positive for mecA. Four MRCNS isolates and the M. caseolyticus isolate grew as off-white colonies on MRSASelect. The remaining colonies, which were initially isolated using the traditional phenotypic testing methods, did not grow on the selective media.

One MRSA isolate was detected from 288 bulk tank milk samples, a $0.3 \%$ prevalence in our total population of dairy herds (exact CI: 0.1-1.9\%). The isolate was obtained from the bulk tank milk on a small organic farm in New York State. Clear differences existed in the RAPD PCR banding patterns of the $m e c A$-positive control and our MRSA suspect field isolate, indicating that they were not the same strain. Multilocus sequence 
Table 1. Descriptive information on the methicillin-resistant Staphylococcus aureus (MRSA) and methicillin-resistant CNS (MRCNS) isolates; results of rpoB sequencing, sequence identity percentage, and microbiological testing ${ }^{1}$

\begin{tabular}{|c|c|c|c|c|c|c|c|c|}
\hline $\begin{array}{l}\text { Farm } \\
\text { identification }\end{array}$ & Isolate & Location & $\begin{array}{l}\text { Farm } \\
\text { status }\end{array}$ & $\begin{array}{l}\text { rpoB } \text { BLAST }^{2} \\
\text { result }\end{array}$ & $\begin{array}{c}\text { Sequence } \\
\text { identity, \% }\end{array}$ & Catalase $^{3}$ & Coagulase $^{4}$ & MRSASelect $t^{5}$ \\
\hline 1 & A & Wisconsin & $\mathrm{CON}$ & Staphylococcus sciuri & 99 & + & - & No \\
\hline 3 & $\mathrm{D}$ & Oregon & ORG & Staph. chromogenes & 99 & + & - & No \\
\hline 3 & $\mathrm{E}$ & Oregon & ORG & Staph. sciuri & 99 & + & - & No \\
\hline 4 & $\mathrm{~F}$ & New York & $\mathrm{CON}$ & Staph. sciuri & 98 & + & - & No \\
\hline 5 & I & New York & ORG & Staph. aureus & 100 & + & + & Yes \\
\hline 6 & $\mathrm{~J}$ & New York & ORG & Staphylococcus saprophyticus & 99 & + & - & Yes \\
\hline 7 & $\mathrm{~K}$ & New York & $\mathrm{CON}$ & Staph. saprophyticus & 99 & + & - & Yes \\
\hline 8 & $\mathrm{~L}$ & Wisconsin & ORG & Macrococcus caseolyticus & 99 & + & - & Yes \\
\hline 9 & M & Wisconsin & $\mathrm{CON}$ & Staph. saprophyticus & 99 & + & - & Yes \\
\hline
\end{tabular}

${ }^{1}$ The isolates presented here were recovered from 288 bulk tank milk samples gathered on organic (ORG) and conventional (CON) farms throughout New York, Wisconsin, and Oregon from March 2009 to May 2011. Methicillin resistance was assessed using a mecA PCR and MRSASelect selective media (Bio-Rad Laboratories Inc., Redmond, WA).

${ }^{2}$ National Center for Biotechnology Information (NCBI), Bethesda, MD (http://blast.ncbi.nlm.nih.gov/Blast.cgi).

${ }^{3}$ Microbiological catalase test.

${ }^{4}$ Microbiological coagulase test.

${ }^{5}$ Growth of the isolate on selective media MRSASelect.

testing determined the MRSA-suspect field isolate to be ST 239 (2-3-1-1-4-4-3), which is the published ST of our mecA positive control (ATCC 33591; Suzuki et al., 2009). Although the ST from the MLST for both the positive control and the field isolate were the same, we believe that these organisms were distinct, as they possessed different RAPD profiles. Previous research has found that staphylococcal isolates of ST 239 may have very different RAPD profiles (Xu et al., 2007).

\section{Notable Findings}

Our research supports the results of a recent study (Haran et al., 2012), which showed a low prevalence of MRSA recovered from bulk tank milk, as well as the results from the National Animal Health Monitoring System (NAHMS) Dairy 2007 study (Virgin et al., 2009). Of the 12 MRCNS isolates, 9 did not grow on MRSASelect, despite a positive mecA PCR. This phenotypic susceptibility and genotypic positive result combination have been previously reported in MRCNS (Sampimon et al., 2011). Staphylococcus sciuri was predominant among our MRCNS isolates (6 isolates out of 12 MRCNS). This is a higher number of methicillin-resistant Staph. sciuri isolated from milk than in previous studies (Piessens et al., 2011; Sampimon et al., 2011). However, Sampimon et al. (2011) assessed clinical mastitis isolates, and not bulk tank samples. Another study found several isolates of Staph. sciuri, but they were predominantly in environmental samples (Piessens et al., 2011). Huber et al. (2011) sampled a variety of different livestock samples in Europe, includ- ing bulk tank milk, and found that $62 \%$ of the milk samples contained MRCNS, but were primarily Staphylococcus fleurettii. All methicillin-resistant Staph. sciuri isolates were detected using only the genotypic method and none grew on the MRSASelect agar. Although this result may seem contradictory, it is common for Staph. sciuri to harbor mecA but display no phenotypic resistance (Tsubakishita et al., 2010b; Sampimon et al., 2011). Macrococcus caseolyticus is a close relative of the Staphylococcus family, has been previously found in bovine milk samples and has had a mec-like element identified (Tsubakishita et al., 2010a), so the presence of this organism was not unexpected.

The presence of Staph. agnetis in our group of isolates is of interest, as it was recently recognized as a new species (Taponen et al., 2012). Additionally, this is the first time that Staph. agnetis has been found in the United States. However, this may be because it was previously misclassified as another organism. No mention was made of the antimicrobial susceptibility to methicillin in the original publication, so we do not know if the methicillin resistance of our isolate is typical of the species or if this is a novel case.

The difference in results from the 2 methods was of interest. Eight of our mecA-positive isolates were recovered from the traditional blood agar and mecA/ nuc screening method, but were not recovered from the phenotypic MRSASelect method. Additionally, 5 isolates were recovered from the MRSASelect method, but not the traditional screening method. This suggests that although both methods have merit in recovering methicillin-resistant staphylococci, neither is $100 \%$ ef- 
fective in recovering all potential methicillin-resistant isolates. Research to elucidate optimal methods for MRSA and MRCNS recovery from milk may be beneficial in the future.

Using a combination of phenotypic and genotypic approaches, we assessed that our population of $288 \mathrm{bulk}$ tank samples had a low prevalence of both MRSA and MRCNS. Although previous research from our study indicated that $55 \%$ of all farms included had Staph. aureus in the bulk tank (Cicconi-Hogan et al., 2013a,b), we have determined that a large majority of this was not MRSA. Our study analyzed a large portion of the US organic industry (approximately $30 \%$ of 3 of the major US dairy-producing states). Overall, 4 organic farms and 5 conventional farms harbored MRCNS in their bulk tank milk, with a prevalence of $2 \%$ on organic farms and $5 \%$ on conventional farms. We conclude that the prevalence of both MRSA and MRCNS in US bulk tank milk is low, despite the high prevalence of Staph. aureus found in the milk from these farms (Cicconi-Hogan et al., 2013a,b) and is no more prevalent in organic or conventional bulk tank milk, based on this study.

\section{ACKNOWLEDGMENTS}

This study was supported by the USDA National Institute of Food and Agriculture (NIFA) Integrated Organic Program (Washington, DC; grant no. 200851106-19463, "Impact of Organic Management on Dairy Animal Health and Well-being") and by a gift from Food Animal Concerns Trust (Chicago, IL). We thank all the farms that participated in the study throughout New York, Vermont, Pennsylvania, Oregon, and Wisconsin. The authors also recognize the efforts of the laboratories at Quality Milk Production Services at Cornell University (Ithaca, NY). We also acknowledge the assistance of Roxann Richert (University of Wisconsin-Madison) and Katie Stiglbauer (Oregon State University, Corvallis) in the collection of field milk samples. Special thanks to Craig Altier (Cornell University, Ithaca NY) for his assistance with testing design and to Abhijit Gurjar (Merck Animal Health, Summit NJ) for his assistance with the RAPD assay. We acknowledge the use of the Staph. aureus MLST database, which is located at Imperial College London (London, UK) and is funded by the Wellcome Trust (London, UK).

\section{REFERENCES}

Brakstad, O. G., K. Aasbakk, and J. A. Maeland. 1992. Detection of Staphylococcus aureus by polymerase chain reaction amplification of the nuc gene. J. Clin. Microbiol. 30:1654-1660.
Carson, J., B. Lui, L. Rosmus, H. Rennick, and J. Fuller. 2009. Interpretation of MRSASelect screening agar at 24 hours of incubation. J. Clin. Microbiol. 47:566-568. http://dx.doi.org/10.1128/ JCM.01566-08.

Cicconi-Hogan, K. M., M. Gamroth, R. Richert, P. L. Ruegg, K. E. Stiglbauer, and Y. H. Schukken. 2013a. Associations of risk factors with somatic cell count in bulk tank milk on organic and conventional dairy farms in the United States. J. Dairy Sci. 96:36893702. http://dx.doi.org/10.3168/jds.2012-6271.

Cicconi-Hogan, K. M., M. Gamroth, R. Richert, P. L. Ruegg, K. E. Stiglbauer, and Y. H. Schukken. 2013b. Risk factors associated with bulk tank standard plate count, bulk tank coliform count and the presence of Staphylococcus aureus on organic and conventional dairy farms in the United States. J. Dairy Sci. http://dx.doi. org/10.3168/jds.2012-6505. 96:7578-7590.

Drancourt, M., and D. Raoult. 2002. rрoB gene sequence-based identification of Staphylococcus species. J. Clin. Microbiol. 40:13331338.

Enright, M. C., N. P. J. Day, C. E. Davies, S. J. Peacock, and B. G. Spratt. 2000. Multilocus sequence typing for characterization of methicillin-resistant and methicillin-susceptible clones of Staphylococcus aureus. J. Clin. Microbiol. 38:1008-1015.

García-Álvarez, L., M. T. Holden, H. Lindsay, C. R. Webb, D. F. Brown, M. D. Curran, E. Walpole, K. Brooks, D. J. Pickard, C. Teale, J. Parkhill, S. D. Bentley, G. F. Edwards, E. K. Girvan, A. M. Kearns, B. Pichon, R. L. Hill, A. R. Larsen, R. L. Skov, S. J. Peacock, D. J. Maskell, and M. A. Holmes. 2011. Methicillinresistant Staphylococcus aureus with a novel mecA homologue in human and bovine populations in the UK and Denmark: A descriptive study. Lancet Infect. Dis. 11:595-603.

Greisen, K., M. Loeffelholz, A. Purohit, and D. Leong. 1994. PCR primers and probes for the 16S rRNA gene of most species of pathogenic bacteria, including bacteria found in cerebrospinal fluid. J. Clin. Microbiol. 32:335-351.

Gurjar, A., G. Gioia, Y. H. Schukken, R. Zadoks, and P. Moroni. 2012. Molecular diagnostics applied to mastitis problems on dairy farms. Vet. Clin. North Am. Food Anim. Pract. 28:565-576.

Haran, K. P.. S. M. Godden, D. Boxrud, S. Jawahir, J. B. Bender, and S. Sreevatsan. 2012. Prevalence and characterization of Staphylococcus aureus, including methicillin-resistant Staphylococcus aureus, isolated from bulk tank milk from Minnesota dairy farms. J. Clin. Microbiol. 50:688-695. http://dx.doi.org/10.1128/ JCM.05214-11.

Huber, H., D. Ziegler, V. Pflüger, G. Vogel, C. Zweifel, and R. Stephan. 2011. Prevalence and characteristics of coagulase-negative staphylococci from livestock, chicken carcasses, bulk tank milk, minced meat and contact persons. BMC Vet. Res. 7:6.

Ito, T., K. Hiramatsu, A. Tomasz, H. de Lencastre, V. Perreten, M. T. G. Holden, D. C. Coleman, R. Goering, P. M. Giffard, R. L. Skov, K. Zhang, H. Westh, F. O'Brien, F. C. Tenover, D. C. Oliveira, S. Boyle-Vavra, F. Laurent, A. M. Kearns, B. Kreiswirth, K. S. Ko, H. Grundmann, J. E. Sollid, J. F. John Jr., R. Daum, B. Soderquist, and G. Buist. 2012. Guidelines for reporting novel mecA gene homologues. Antimicrob. Agents Chemother. 56:4997-4999. http://dx.doi.org/10.1128/AAC.01199-12.

Kreausukon, K., A. Fetsch, B. Kraushaar, K. Alt, K. Müller, V. Krömker, K.-H. Zessin, A. Käsbohrer, and B.-A. Tenhagen. 2012. Prevalence, antimicrobial resistance, and molecular characterization of methicillin-resistant Staphylococcus aureus from bulk tank milk of dairy herds. J. Dairy Sci. 95:4382-4388. http://dx.doi. org/10.3168/jds.2011-5198.

Martineau, F., F. J. Picard, N. Lansac, C. Ménard, P. H. Roy, M. Ouellette, and M. G. Bergeron. 2000. Correlation between the resistance genotype determined by multiplex PCR assays and the antibiotic susceptibility patterns of Staphylococcus aureus and Staphylococcus epidermidis. Antimicrob. Agents Chemother. 44:231-238.

Paterson, G. K., A. R. Larsen, A. Robb, G. E. Edwards, T. W. Pennycott, G. Foster, D. Mot, K. Hermans, K. Baert, S. J. Peacock, J. Parkhill, R. N. Zadoks, and M. A. Holmes. 2012. The newly described $m e c A$ homologue, $m e c A_{\mathrm{LGA} 251}$, is present in methicillin- 
resistant Staphylococcus aureus isolates from a diverse range of host species. J. Antimicrob. Chemother. 67:2809-2813. http:// dx.doi.org/10.1093/jac/dks329.

Pérez-Roth, E., F. Claverie-Martín, J. Villar, and S. Méndez-Alvarez. 2001. Multiplex PCR for simultaneous identification of Staphylococcus aureus and detection of methicillin and mupirocin resistance. J. Clin. Microbiol. 39:4037-4041. http://dx.doi. org/10.1128/JCM.39.11.4037-4041.2001.

Piessens, V., E. Van Coillie, B. Verbist, K. Supré, G. Braem, A. Van Nuffel, L. De Vuyst, M. Heyndrickx, and S. De Vliegher. 2011. Distribution of coagulase-negative Staphylococcus species from milk and environment of dairy cows differs between herds. J. Dairy Sci. 94:2933-2944. http://dx.doi.org/10.3168/jds.2010-3956.

Richert, R. M., K. M. Cicconi, M. J. Gamroth, Y. H. Schukken, K. E. Stiglbauer, and P. L. Ruegg. 2013. Management factors associated with veterinary usage by organic and conventional dairy farms. J. Am. Vet. Med. Assoc. 242:1732-1743. http://dx.doi.org/10.2460/ javma.242.12.1732.

Ruegg, P. L. 2009. Management of mastitis on organic and conventional dairy farms. 2009. J. Anim. Sci. 87:43-55.

Sampimon, O. C., T. J. G. M. Lam, D. J. Mevius, Y. H. Schukken, and R. N. Zadoks. 2011. Antimicrobial susceptibility of coagulase-negative staphylococci isolated from bovine milk samples. Vet. Microbiol. 150:173-179. http://dx.doi.org/10.1016/j. vetmic.2011.01.017.

Sato, K., T. W. Bennedsgaard, P. C. Bartlett, R. J. Erskine, and J. B. Kaneene. 2004. Comparison of antimicrobial susceptibility of Staphylococcus aureus isolated from bulk tank milk in organic and conventional dairy herds in the midwestern United States and Denmark. J. Food Prot. 67:1104-1110.

Spohr, M., J. Rau, A. Friedrich, G. Klittich, A. Fetsch, B. Guerra, J. A. Hammerl, and B.-A. Tenhagen. 2011. Methicillin-resistant Staphylococcus aureus (MRSA) in three dairy herds in southwest Germany. Zoonoses Public Health 58:252-261. http://dx.doi. org/10.1111/j.1863-2378.2010.01344.x.

Stiglbauer, K. E., K. M. Cicconi-Hogan, R. Richert, Y. H. Schukken, P. L. Ruegg, and M. Gamroth. 2013. Assessment of herd management on organic and conventional dairy farms in the United States. J. Dairy Sci. 96:1290-1300. http://dx.doi.org/10.3168/ jds.2012-5845.

Suzuki, M., M. Matsumoto, M. Takahashi, Y. Hayakawa, and H. Minagawa. 2009. Identification of the clonal complexes of Staphylo- coccus aureus strains by determination of the conservation of patterns of small genomic islands. J. Appl. Microbiol. 107:1367-1374.

Taponen, S., K. Supré, V. Piessens, E. Van Coillie, S. De Vliegher, and J. M. K. Koort. 2012. Staphylococcus agnetis sp. nov., a coagulasevariable species from bovine subclinical and mild clinical mastitis. Int. J. Syst. Evol. Microbiol. 62:61-65. http://dx.doi.org/10.1099/ ijs.0.028365-0.

Tikofsky, L. L., J. W. Barlow, C. Santisteban, and Y. H. Schukken. 2003. A comparison of antimicrobial susceptibility patterns for Staphylococcus aureus in organic and conventional dairy herds. Microb. Drug Resist. 9:S39-S45.

Tsubakishita, S., K. Kuwahara-Arai, T. Baba, and K. Hiramatsu. 2010a. Staphylococcal cassette chromosome mec-like element in Macrococcus caseolyticus. Antimicrob. Agents Chemother. 54:1469-1475. http://dx.doi.org/10.1128/AAC.00575-09.

Tsubakishita, S., K. Kuwahara-Arai, T. Sasaki, and K. Hiramatsu. 2010b. Origin and molecular evolution of the determinant of methicillin resistance in staphylococci. Antimicrob. Agents Chemother. 54:4352-4359. http://dx.doi.org/10.1128/AAC.00356-10.

USDA-ERS (USDA Economic Research Service). 2013. Organic production. Accessed Nov. 19, 2013. http://www.ers.usda.gov/dataproducts/organic-production.aspx\#.UoucUZHFkpF.

Virgin, J. E., T. M. Van Slyke, J. E. Lombard, and R. N. Zadoks. 2009. Short communication: Methicillin-resistant Staphylococcus aureus detection in US bulk tank milk. J. Dairy Sci. 92:4988-4991. http://dx.doi.org/10.3168/jds.2009-2290.

Wolk, D. M., J. L. Marx, L. Dominguez, D. Driscoll, and R. B. Schifman. 2009. Comparison of MRSA Select agar, CHROMagar methicillin-resistant Staphylococcus aureus (MRSA) medium, and Xpert MRSA for detection of methicillin resistant Staphylococcus aureus (MRSA) in nares: Diagnostic accuracy for surveillance samples with various bacterial densities. J. Clin. Microbiol. 47:3933-3936.

Xu, Z., L. Shi, C. Zhang, L. Zhang, X. Li, Y. Cao, L. Li, and S. Yamasaki. 2007. Nosocomial infection caused by class 1 integroncarrying Staphylococcus aureus in a hospital in South China. Clin. Microbiol. Infect. 13:980-984. http://dx.doi.org/10.1111/j.14690691.2007.01782.x.

Zwald, A. G., P. L. Ruegg, J. B. Kaneene, L. D. Warnick, S. J. Wells, C. Fossler, and L. W. Halbert. 2004. Management practices and reported antimicrobial usage on conventional and organic dairy farms. J. Dairy Sci. 87:191-201. http://dx.doi.org/10.3168/jds. S0022-0302(04)73158-6. 